\title{
0929 THE CONTRIBUTION OF AN INJURY DATA REGISTRY SYSTEM TO INJURY SURVEILLANCE IN RURAL IRAN: COMMUNITY HEALTH WORKERS AND HEALTH AUTHORITIES VIEWS AND CONCERNS
}

F Rezapur-Shahkolai*, M Naghavi, M Shokouhi, L Laflamme Correspondence: Department of Public Health, School of Public Health and Center for Health Research, Hamadan University of Medical Sciences, Hamadan 65178/518, Iran

\subsection{6/ip.2010.029215.929}

Background Injury prevention and control require that accurate data be continuously gathered, analysed and disseminated. A new injury data registry system has recently been piloted and is in the progress of being implemented in rural areas of Iran. This study aims at highlighting areas of consensus and of differences of opinion between different groups of stakeholders concerning the new registration systems potential for injury surveillance and control.

Methods This interview-based study gathered the opinions of stakeholders from national, provincial, and district levels, including community health workers (called Behvarzes) concerning the acceptance, functioning and potential for injury prevention of the new system. The answers provided by all respondents except for the heads of villages are considered (64 Behvarzes and 27 other stakeholders). Attention was paid to the answers provided regarding the acceptance of the injury information system; the weaknesses and strengths identified, and the facilitators and barriers for it to be integrated into the work of the community health workers.

Results Most Behvarzes (53 of 64) and about half of the other stakeholders (13 of 27) expressed positive opinions regarding their acceptance of the system. Consensuses between the two groups of respondents were stronger regarding the potential of the system to determine the incidence of specific types of injuries; and also the sex and age related injury distributions. Most interviewees also considered that the system could provide data of interest for future injury control and prevention. The facilitator of the system most frequently mentioned was the Behvarzes, who come from the local community and reside there. Nonetheless, their high workload and multiple tasks in the health house were regarded as likely barriers to their commitment to the system. Behvarzes mentioned that they would appreciate feed back about the information they gather, in the form of for example reports from upper level authorities, in particular about how that information affects injury control and prevention at community level. 